\title{
Use of online cultural content for mental health and well-being during COVID-19 restrictions: cross-sectional survey
}

\author{
Rebecca J. Syed Sheriff, ${ }^{1,2,3}$ (1) Helen Adams, ${ }^{1}$ Evgenia Riga, ${ }^{1}$ Andrew K. Przybylski, ${ }^{1}$ Laura Bonsaver, \\ Laura Bergin, ${ }^{1}$ Bessie O'Dell, ${ }^{1}$ Susan McCormack, ${ }^{1}$ Cathy Creswell, (0) Andrea Cipriani, ${ }^{1}$ (1) \\ John R. Geddes ${ }^{1}$
}

BJPsych Bulletin (2022) 46, 278-287, doi:10.1192/bjb.2021.103

${ }^{1}$ University of Oxford, UK; ${ }^{2}$ Oxford Health NHS Foundation Trust, UK; ${ }^{3}$ University of Nottingham, UK

Correspondence to Rebecca J. Syed Sheriff (rebecca.sheriff@psych.ox.ac.uk)

First received 26 Feb 2021, final revision 15 Sep 2021, accepted 8 Oct 2021

(c) The Author(s), 2021. Published by Cambridge University Press on behalf of the Royal College of Psychiatrists. This is an Open Access article, distributed under the terms of the Creative Commons Attribution licence (https:// creativecommons.org/licenses/by/4. $0 /$ ), which permits unrestricted re-use, distribution, and reproduction in any medium, provided the original work is properly cited.

\begin{abstract}
Aims and method To gain a deeper understanding of the use of online culture and its potential benefits to mental health and well-being, sociodemographic characteristics and self-reported data on usage, perceived mental health benefits and health status were collected in an online cross-sectional survey during COVID-19 restrictions in the UK in June-July 2020.
\end{abstract}

Results In total, 1056 people completed the survey. A high proportion of participants reported finding online culture helpful for mental health; all but one of the benefits were associated with regular use and some with age. Reported benefits were wide-ranging and interconnected. Those aged under 25 years were less likely to be regular users of online culture or to have increased their use during lockdown.

Clinical implications There may be benefits in targeting cultural resources for mental health to vulnerable groups such as young adults.

Keywords Culture; museum; online; distress; mental health.
Even before the COVID-19 pandemic, mental health was a major public health priority. ${ }^{1}$ Mental health problems have been exacerbated in the context of the COVID-19 pan$\operatorname{demic}^{2,3}$ and are set to remain a major public health concern, particularly among those most vulnerable, post-COVID-19. ${ }^{4}$

The first UK lockdown, initiated in March 2020, and subsequent restrictions forced the public indoors, leaving millions feeling isolated. ${ }^{5}$ Concurrently, the closure of cultural institutions such as museums, theatres and art galleries led to a rapid increase in both the production of, and engagement with, online culture. For example, in less than a month after it closed owing to the pandemic, the Metropolitan Museum of Art in New York reported a $4106 \%$ growth in streaming viewership, while the Ashmolean Museum in Oxford saw a huge increase in social media followers from March to July 2020, initiating the beginning of a new era' of virtual engagement for cultural institutions. ${ }^{6}$ With isolation being one of the biggest concerns during lockdown, ${ }^{7}$ many cultural institutions sought to find ways to bring people together to improve mental well-being. As Ernesto Ottone Ramírez, Assistant Director-General for Culture at UNESCO, said:

'At a time when billions of people are physically separated from one another, culture has brought us together, keeping us connected and shortening the distance between us. It has provided comfort, inspiration and hope at a time of enormous anxiety and uncertainty.,

Currently, there is no consensus on a single definition of well-being. There is general agreement that the concept includes the presence of positive emotions and moods (such as contentment and happiness), the absence of negative emotions (such as depression and anxiety), satisfaction with life, fulfilment and positive functioning, at a minimum. ${ }^{9}$ There are controversies in defining the term mental health, although one survey ${ }^{10}$ reported the preferred definition to be: 'the capacity of each and all of us to feel, think, and act in ways that enhance our ability to enjoy life and deal with the challenges we face. It is a positive sense of emotional and spiritual well-being that respects the importance of culture, equity, social justice, interconnections and personal dignity..11

The concept that culture and the arts are good for us is not new. ${ }^{12}$ Evidence for this view pervades the history of ideas dating back to Aristotle, who wrote that it is the natural instinct of all to 'delight in works of imitation'.12,13 Kant described how the enjoyment of art can enhance personal well-being through pleasurable experience, ${ }^{12}$ and Schopenhauer describes art as one of the few means of protection from the anguish brought about by the unbearable nature of the human condition. ${ }^{12,14}$ Although there is a 
general academic view that culture has a positive effect on health and well-being, ${ }^{15,16}$ there have been long-standing debates regarding potentially adverse effects, including issues of inequitable provision and appreciation. This includes Bourdieu's theories of how cultural tastes originate in and perpetuate social stratification and thus may reinforce social hierarchies. ${ }^{17}$

However well-established these concepts of the positive effects of culture consumption are in the collective consciousness, there are significant research gaps regarding the effects of the arts and culture on health. Many studies have demonstrated correlations between cultural engagement and improved mental and physical health and longer life expectancy, but most are confounded by the sociodemographic determinants of health. ${ }^{9}$ More bluntly put, owing to inequitable access, ${ }^{18,19}$ those most likely to use culture and the arts are those at lower risk of poor health outcomes by virtue of characteristics such as income, education and ethnicity. ${ }^{9}$ Consequently, at the population level those least likely to be accessing these resources may be those most likely to benefit from them. It is also possible that the mechanisms by which those in particular sociodemographic groups have improved health outcomes relate to the richness of existence offered by such experiences.

Another flaw in much of the literature in this area has been such broad and non-specific definition of arts and culture as to obfuscate interpretation of the mental health effects. ${ }^{9}$ In the present paper, online cultural content refers to online resources from cultural institutions and includes museums, theatres, art galleries, libraries, archives and natural heritage organisations. In an attempt to avoid the pitfalls of casting too wide a net, this is a narrower definition than that adopted by others ${ }^{20}$ which can also include reading, films and gaming. ${ }^{20}$

Much of the published work in the area of cultural engagement and mental health is in the form of communitybased projects or pilot schemes for users of health services. Many of these involve social prescribing visits to cultural institutions $^{21}$ in clinical populations. ${ }^{22-25}$ However, while the evidence regarding potential benefits of the arts on mental health in clinical populations is growing, ${ }^{15,26-32}$ a substantial body of evidence suggests that people with the greatest mental health need often have the poorest access to health services. ${ }^{33}$ Thus, concentrating research on clinical populations and social prescribing initiatives ${ }^{34}$ risks missing major opportunities to reduce health inequalities at the population level and may even compound such inequalities. In addition, it also represents a missed opportunity for prevention of mental illness and self-management of mental health.

\section{Aim and objectives}

In light of the accelerated pace with which cultural institutions had expanded their online presence during the COVID-19 pandemic and building on the foundations of work to identify the health value of engaging with culture and the arts, we set out to describe who was using online cultural content, the perceived mental health benefits and the self-reported mental health of people using online culture during this period. To this end we conducted an online cross-sectional survey between 17 June and 22 July 2020.
During that time the UK was not under full lockdown, but social distancing measures were in place and UK museums were closed.

Given the paucity of studies in this area, the aims of this study were primarily exploratory, to describe users of online culture, factors associated with being a regular user and increased engagement during the COVID-19 pandemic, selfreported benefits and the mental health status of this population.

\section{Method \\ Ethical approval}

The authors assert that all procedures contributing to this work comply with the ethical standards of the relevant national and institutional committees on human experimentation and with the Helsinki Declaration of 1975, as revised in 2008. All procedures involving human participants were approved by the Medical Sciences Interdivisional Research Ethics Committee of the University of Oxford (approval reference R70187/RE001-3).

\section{Procedure}

We recruited 1056 participants aged 16 and over in the UK (or 18 and over, overseas) for the initial survey between 17 June and 22 July 2020. Participants were recruited through Facebook adverts, a press release, a pop-up advert that appeared on the Ashmolean Museum website, as well as the Ashmolean's public relations avenues (e.g. Twitter and a newsletter) and student unions. To enter the survey, participants followed a link to e-consent procedures (web traffic to the survey is shown in supplementary Table 1, available at https://doi.org/10.1192/bjb.2021.103). Of the 1056 participants, 500 chose to enter their email address and consented to be contacted again for further research. These people were emailed a link to e-consent to participate in a further free-text survey and 176 participants completed this survey between 10 and 30 July 2020.

\section{Measures}

The initial survey included items on sociodemographics, usage and changes of use of online cultural content, health status and items on how online culture was perceived to affect on mental health and well-being. Sociodemographic items included age, gender, ethnicity, highest educational attainment, household income and the number of people living in the household. Questions relating to health status included COVID-19 isolation status, physical health problems and disability, as well as a measure of psychological distress.

A wide range of potential ways in which online cultural content could be helpful for mental health were offered as options, as well as an option with free-text boxes inviting participants to describe other ways online culture could be helpful for mental health. Items were also included comparing online with in-person experiences and whether benefits would be improved by including other people in the experience. The separate free-text survey was formulated to gain 
Table 1 Population characteristics $(n=1056)$

\begin{tabular}{|c|c|c|c|c|}
\hline & \multirow[b]{2}{*}{$n$} & \multirow[b]{2}{*}{$\%$} & \multicolumn{2}{|c|}{$95 \% \mathrm{Cl}$} \\
\hline & & & Lower & Upper \\
\hline \multicolumn{5}{|l|}{ Age group, years } \\
\hline $16-24$ & 77 & 7.4 & 5.9 & 9.1 \\
\hline $25-34$ & 73 & 7.0 & 5.6 & 8.7 \\
\hline $35-44$ & 88 & 8.4 & 6.9 & 10.3 \\
\hline $45-54$ & 152 & 14.6 & 12.5 & 16.8 \\
\hline $55-64$ & 294 & 28.2 & 25.5 & 31.0 \\
\hline 65 and over & 360 & 34.5 & 31.7 & 37.4 \\
\hline \multicolumn{5}{|l|}{ Gender } \\
\hline Male & 182 & 17.4 & 15.2 & 19.9 \\
\hline Female & 855 & 81.9 & 79.4 & 84.1 \\
\hline Other & 7 & 0.7 & 0.3 & 1.4 \\
\hline Prefer not to say & 12 & 1.1 & & \\
\hline \multicolumn{5}{|l|}{ Annual household income } \\
\hline Less than $£ 16000$ & 107 & 13.0 & 10.8 & 15.4 \\
\hline$€ 16000-£ 29999$ & 190 & 23.0 & 20.3 & 26.0 \\
\hline$£ 30000-£ 59999$ & 272 & 32.9 & 29.8 & 36.2 \\
\hline$£ 60000-£ 119999$ & 133 & 16.1 & 13.7 & 18.8 \\
\hline More than $E 120 \mathrm{~K}$ & 124 & 15.0 & 12.7 & 17.6 \\
\hline Prefer not to say & 230 & & & \\
\hline \multicolumn{5}{|l|}{ Highest educational attainment } \\
\hline $\begin{array}{l}\text { No qualification/vocational or } \\
\text { school qualification }\end{array}$ & 155 & 14.8 & 12.8 & 17.1 \\
\hline University degree & 891 & 85.2 & 82.9 & 87.2 \\
\hline Prefer not to say & 10 & & & \\
\hline \multicolumn{5}{|l|}{ Ethnicity } \\
\hline Asian & 18 & 1.7 & 1.1 & 2.7 \\
\hline Black & 1 & 0.1 & 0.0 & 0.7 \\
\hline Chinese & 7 & 0.7 & 0.3 & 1.4 \\
\hline White British, Irish, Other & 961 & 91.0 & 89.1 & 92.6 \\
\hline Mixed-race White and Black & 0 & 0.0 & & \\
\hline Mixed-race Other & 28 & 2.7 & 1.8 & 3.8 \\
\hline Middle Eastern & 6 & 0.6 & 0.3 & 1.3 \\
\hline Other/prefer not to say & 35 & 3.3 & 2.4 & 4.6 \\
\hline \multicolumn{5}{|l|}{ Location } \\
\hline East Midlands & 55 & 5.2 & 4.0 & 6.7 \\
\hline East of England & 37 & 3.5 & 2.5 & 4.8 \\
\hline Greater London & 88 & 8.3 & 6.8 & 10.2 \\
\hline North East England & 22 & 2.1 & 1.4 & 3.1 \\
\hline Northern Ireland & 4 & 0.4 & 0.1 & 1.0 \\
\hline North West England & 50 & 4.7 & 3.6 & 6.2 \\
\hline Scotland & 32 & 3.0 & 2.1 & 4.3 \\
\hline South East England & 323 & 30.6 & 27.9 & 33.4 \\
\hline South West England & 123 & 11.6 & 9.8 & 13.7 \\
\hline Wales & 22 & 2.1 & 1.4 & 3.1 \\
\hline West Midlands & 69 & 6.5 & 5.2 & 8.2 \\
\hline Yorkshire and the Humber & 26 & 2.5 & 1.7 & 3.6 \\
\hline
\end{tabular}

Table 1 Continued

$95 \% \mathrm{Cl}$

\begin{tabular}{lrrrr} 
& & & \multicolumn{2}{c}{$95 \% \mathrm{Cl}$} \\
\cline { 5 - 6 } & $n$ & $\%$ & Lower & Uppe \\
\hline Outside of UK & 205 & 19.4 & 17.1 & 21.9 \\
\hline Type of area & & & & \\
\hline City & 392 & 37.3 & 34.5 & 40.3 \\
\hline Large town & 173 & 16.5 & 14.3 & 18.8 \\
\hline Small town & 222 & 21.1 & 18.8 & 23.7 \\
\hline Village & 210 & 20.0 & 17.7 & 22.5 \\
\hline Rural (hamlet or isolated & 53 & 5.0 & 3.9 & 6.6
\end{tabular}

dwelling)

Missing 6

Household

\begin{tabular}{lllll}
\hline Living alone & 241 & 22.8 & 20.4 & 25.5 \\
\hline Living with one other & 629 & 59.6 & 56.6 & 62.5 \\
\hline
\end{tabular}

\begin{tabular}{lllll} 
Living with more than one other & 186 & 17.6 & 15.4 & 20.0 \\
\hline
\end{tabular}

Previous COVID-19 infection

\begin{tabular}{lrrrr}
\hline No & 933 & 88.4 & 86.4 & 90.2 \\
\hline Yes or suspected & 122 & 11.6 & 9.8 & 13.6 \\
\hline Missing & 1 & & & \\
\hline
\end{tabular}

Isolation status

\begin{tabular}{lrrrr}
\hline Full isolation & 76 & 7.3 & 5.8 & 9.0 \\
\hline Restricted & 643 & 61.4 & 58.4 & 64.3 \\
\hline Leaving more often & 329 & 31.4 & 28.6 & 34.3 \\
\hline Missing & 8 & & & \\
\hline
\end{tabular}

Employment status

\begin{tabular}{lrrrr}
\hline Full-time education & 79 & 7.6 & 6.1 & 9.3 \\
\hline Employed & 441 & 42.2 & 39.2 & 45.2 \\
\hline $\begin{array}{l}\text { Unemployed/unwell/furlough/ } \\
\text { homemaker }\end{array}$ & 128 & 12.2 & 10.4 & 14.4 \\
\hline
\end{tabular}

\begin{tabular}{ccccc}
\hline Retired & 398 & 38.0 & 35.1 & 41.0 \\
\hline
\end{tabular}

Prefer not to say

10

Physical health problem/disability

\begin{tabular}{lrrrr}
\hline No & 834 & 80.3 & 77.7 & 82.6 \\
\hline Yes & 205 & 19.7 & 17.4 & 22.3 \\
\hline
\end{tabular}

Prefer not to say

$17 \quad 1.6$

Mental health problems

\begin{tabular}{lllll}
\hline No & 872 & 84.0 & 81.6 & 86.1 \\
\hline Yes & 166 & 16.0 & 13.9 & 18.4 \\
\hline
\end{tabular}

Prefer not to say

18

Kessler Psychological Distress Scale score

\begin{tabular}{lrrrr}
\hline$<20$ & 583 & 56.0 & 53.0 & 59.0 \\
\hline $20-24$ & 217 & 20.8 & 18.5 & 23.4 \\
\hline $25-29$ & 123 & 11.8 & 10.0 & 13.9 \\
\hline$\geq 30$ & 118 & 11.3 & 9.5 & 13.4 \\
\hline Missing & 15 & & & \\
\hline
\end{tabular}

Change in use of online culture since initiation of COVID-19 restrictions

\begin{tabular}{lllll} 
Increased & 753 & 71.3 & 68.5 & 74.0 \\
\hline
\end{tabular} Continued 


\begin{tabular}{|lrrrrr}
\hline Table 1 Continued & & & & \\
& & & $95 \%$ & $\mathrm{Cl}$ \\
\cline { 3 - 5 } & $n$ & $\%$ & Lower & Upper \\
\hline Same & 241 & 22.8 & 20.4 & 25.5 \\
\hline Less & 62 & 5.9 & 4.6 & 7.5 \\
\hline Use of online culture & & & & \\
\hline Daily & 247 & 23.4 & 20.9 & 26.0 \\
\hline Once a week or more & 432 & 40.9 & 38.0 & 43.9 \\
\hline Once a month or more & 176 & 16.7 & 14.5 & 19.0 \\
\hline Less than once a month & 201 & 19.0 & 16.8 & 21.5 \\
\hline In-person museum use & & & & \\
\hline Visit in previous year & 482 & 45.6 & 42.7 & 48.8 \\
\hline
\end{tabular}

richer data on which and how cultural content could benefit mental health online or in person (if different from online).

Current self-reported psychological distress was measured in the initial survey using the Kessler Psychological Distress Scale (K10). The K10 strongly discriminates between community cases and non-cases of mental disorder identified by a structured clinical interview. ${ }^{35}$ The K10 comprises ten questions inquiring about the frequency of depressive and anxiety symptoms over the previous 4 weeks. Each item is rated on a 5-point Likert scale (1, none of the time; 5 , all of the time) and scores are added to give a possible range of $10-50$, with higher scores reflecting higher levels of psychological distress. The K10 is one of the most widely used mental health screening instruments ${ }^{36}$ and demonstrates good properties with regard to validity, reliability ${ }^{36}$ and sensitivity to change. ${ }^{37}$ A K10 score $\geq 20$ was defined as clinically significant distress. ${ }^{35,36}$

\section{Statistical analysis}

Data were imported into Stata v16.0 and descriptive statistics were used to describe the sociodemographic characteristics of the population. Percentages (and 95\% confidence intervals) were calculated for population characteristics such as age, gender, income, education, ethnicity, location, employment status, household size, mental and physical health and isolation status, as well as online culture usage.

We used logistic regression techniques to analyse associations between sociodemographic and health variables and regular use of online culture (once a month or more) and increased engagement with online cultural content during COVID-19 restrictions. We described the percentage reporting specific mental health benefits of online culture. We used logistic regression techniques to examine the association of these with regular engagement and age group.

Logistic regression techniques were performed to analyse associations between clinically significant psychological distress, defined as scoring $\geq 20$ on the $\mathrm{K} 10,{ }^{36,38}$ and sociodemographic and individual characteristics.

\section{Free-text analysis}

Participants' free-text responses for both surveys were pseudo-anonymised, with each response assigned a unique ID. The free-text responses were imported into NVivo 12 software for MacOS (QSR International, www.qsrinternational.com) to facilitate organisation and analysis of data. Two researchers (L.B. and B.O'D.) qualitatively analysed the free-text data by independently performing an inductive thematic analysis, ${ }^{39}$ allowing prevailing themes from the collected free text to be identified and subsequently analysed. All free-text responses were coded into themes, providing an initial framework for the qualitative data, with multiple allocations possible. This initial qualitative framework was then discussed collaboratively by the team to discern patterns in the data. The framework continued to be developed and refined to reflect the themes emerging from the free text, as well as the relationships between themes.

\section{Results}

In total, 1056 participants completed the initial survey (between 17 June and 22 July 2020). High proportions of participants were over 44 years of age, female, had a university degree, reported being of White (British, Irish or Other) ethnic background and living with at least one other person. Of those who reported household income, the majority had a household income over $£ 30000$ per year (Table 1).

A high proportion of participants reported using online culture once a month or more (80.9\%, 95\% CI 78.5-83.2). This was associated with being older than 24 , being female, having a household income of over $£ 30000$ per year, having a university degree, being of White (British, Irish or Other) ethnicity and reporting an in-person museum visit in the previous year (Table 2).

In addition, a high proportion of participants reported increasing their use of online culture since the initiation of COVID-19 restrictions (71.3\%, 95\% CI 68.5-74.0) Increased use was associated with being over 45, being female, having a household income of over $£ 30000$ per year, being of White (British, Irish or other) ethnicity and being unemployed, unwell, on furlough or a homemaker and reporting an in-person visit in the previous year (Table 2).

A high proportion of participants reported that online cultural content was helpful for mental health and wellbeing. All bar one of the 15 most frequently reported mental health benefits were significantly associated with regular use of online culture (Table 3). In addition, there were significant differences in the benefits reported according to age, even when regular of use of online culture was controlled for. There were lower odds of people aged 25-34 reporting 'feeling connected' than other age groups (adjusted $\mathrm{OR}=0.37$, 95\% CI 0.15-0.87) and lower odds of those in lower age groups reporting benefits due to adding structure to their day $(\mathrm{aOR}=0.16,95 \% \mathrm{CI}$ 0.15-0.70). There were lower odds of reporting benefits due to increased personal productivity (aOR $=0.46,95 \%$ CI $0.22-0.94)$ in those aged 55 and over compared with people aged 16-24. 
Table 2 Associations between population characteristics and consumption of online cultural content ${ }^{\mathrm{a}}$

\begin{tabular}{|c|c|c|c|c|c|c|c|}
\hline \multirow[b]{2}{*}{ Characteristic } & \multirow[b]{2}{*}{ Variable } & \multirow{2}{*}{$\begin{array}{c}\text { OR of using online } \\
\text { culture once a month or } \\
\text { more }\end{array}$} & \multicolumn{2}{|c|}{$95 \% \mathrm{Cl}$} & \multirow{2}{*}{$\begin{array}{l}\text { OR of increased use of online } \\
\text { culture in COVID-19 context }\end{array}$} & \multicolumn{2}{|c|}{$95 \% \mathrm{Cl}$} \\
\hline & & & Lower & Upper & & Lower & Upper \\
\hline \multicolumn{8}{|l|}{ Age group, years } \\
\hline & $16-24$ & 1.00 & & & 1.00 & & \\
\hline & $25-34$ & 3.06 & 1.48 & 6.31 & 1.59 & 0.82 & 3.06 \\
\hline & $35-44$ & 3.85 & 1.88 & 7.87 & 1.61 & 0.86 & 3.02 \\
\hline & $45-54$ & 3.50 & 1.91 & 6.44 & 2.83 & 1.58 & 5.07 \\
\hline & $55-64$ & 4.05 & 2.35 & 6.99 & 2.66 & 1.58 & 4.47 \\
\hline & 65 and over & 4.03 & 2.38 & 6.85 & 2.35 & 1.42 & 3.89 \\
\hline Gender & Female & 1.64 & 1.12 & 2.38 & 1.86 & 1.33 & 2.59 \\
\hline $\begin{array}{l}\text { Annual household } \\
\text { income }\end{array}$ & More than $£ 30000$ & 1.56 & 1.13 & 2.17 & 1.52 & 1.14 & 2.02 \\
\hline $\begin{array}{l}\text { Highest educational } \\
\text { attainment: }\end{array}$ & $\begin{array}{l}\text { Undergraduate or } \\
\text { postgraduate degree }\end{array}$ & 1.64 & 1.11 & 2.41 & 0.99 & 0.68 & 1.43 \\
\hline Ethnicity & $\begin{array}{l}\text { White British, Irish and } \\
\text { other }\end{array}$ & 1.69 & 1.05 & 2.73 & 1.59 & 1.02 & 2.46 \\
\hline Country & UK & 1.08 & 0.73 & 1.61 & 0.91 & 0.65 & 1.27 \\
\hline \multicolumn{8}{|l|}{ Type of area } \\
\hline & City & 1.00 & & & & & \\
\hline & Large town & 0.81 & 0.52 & 1.26 & 1.23 & 0.82 & 1.82 \\
\hline & Small town & 0.95 & 0.63 & 1.45 & 1.21 & 0.84 & 1.74 \\
\hline & Village & 1.07 & 0.69 & 1.66 & 1.23 & 0.85 & 1.78 \\
\hline & $\begin{array}{l}\text { Rural (hamlet or isolated } \\
\text { dwelling) }\end{array}$ & 1.29 & 0.58 & 2.85 & 1.41 & 0.73 & 2.73 \\
\hline Household & Live alone & 1.11 & 0.76 & 1.61 & 0.93 & 0.68 & 1.27 \\
\hline $\begin{array}{l}\text { Previous COVID-19 } \\
\text { infection }\end{array}$ & Yes or suspected & 0.69 & 0.44 & 1.07 & 0.80 & 0.53 & 1.20 \\
\hline \multicolumn{8}{|l|}{ Isolation status } \\
\hline & Full isolation & 1.00 & & & 1.00 & & \\
\hline & Restricted & 1.07 & 0.57 & 2.01 & 0.93 & 0.54 & 1.62 \\
\hline & Leaving more often & 0.60 & 0.32 & 1.15 & 0.63 & 0.36 & 1.11 \\
\hline \multicolumn{8}{|l|}{ Employment status } \\
\hline & Full time education & 1.00 & & & 1.00 & & \\
\hline & Employed & 1.66 & 0.95 & 2.89 & 1.46 & 0.89 & 2.41 \\
\hline & $\begin{array}{l}\text { Unemployed/unwell/ } \\
\text { furlough/homemaker }\end{array}$ & 1.35 & 0.70 & 2.61 & 1.92 & 1.04 & 3.52 \\
\hline & Retired & 1.64 & 0.94 & 2.87 & 1.58 & 0.96 & 2.62 \\
\hline Physical disability & Yes & 0.65 & 0.45 & 0.93 & 1.14 & 0.81 & 1.61 \\
\hline $\begin{array}{l}\text { Mental health } \\
\text { problems }\end{array}$ & Yes & 0.75 & 0.50 & 1.12 & 0.80 & 0.56 & 1.14 \\
\hline K10 score & $>19$ & 0.78 & 0.58 & 1.07 & 1.09 & 0.83 & 1.42 \\
\hline In-person use & Visit in previous year & 1.76 & 1.28 & 2.43 & 1.57 & 1.19 & 2.06 \\
\hline
\end{tabular}

K10, Kessler Psychological Distress Scale.

a. Bold denotes significant difference identified based on odds ratio.

Having a clinically significant level of distress (a K10 score of $\geq 20$ ) was associated with being younger than 35 , female, a household annual income below £30 000, belonging to a Black, Asian, Middle Eastern, mixed or other ethnic group, not having a university degree, being in full-time education, previous COVID-19 infection (diagnosed or suspected), self-isolating and having a mental or physical health problem/disability (Table 4). Reporting an in-person museum visit in the previous year had an inverse relationship with a clinically significant level of distress. 


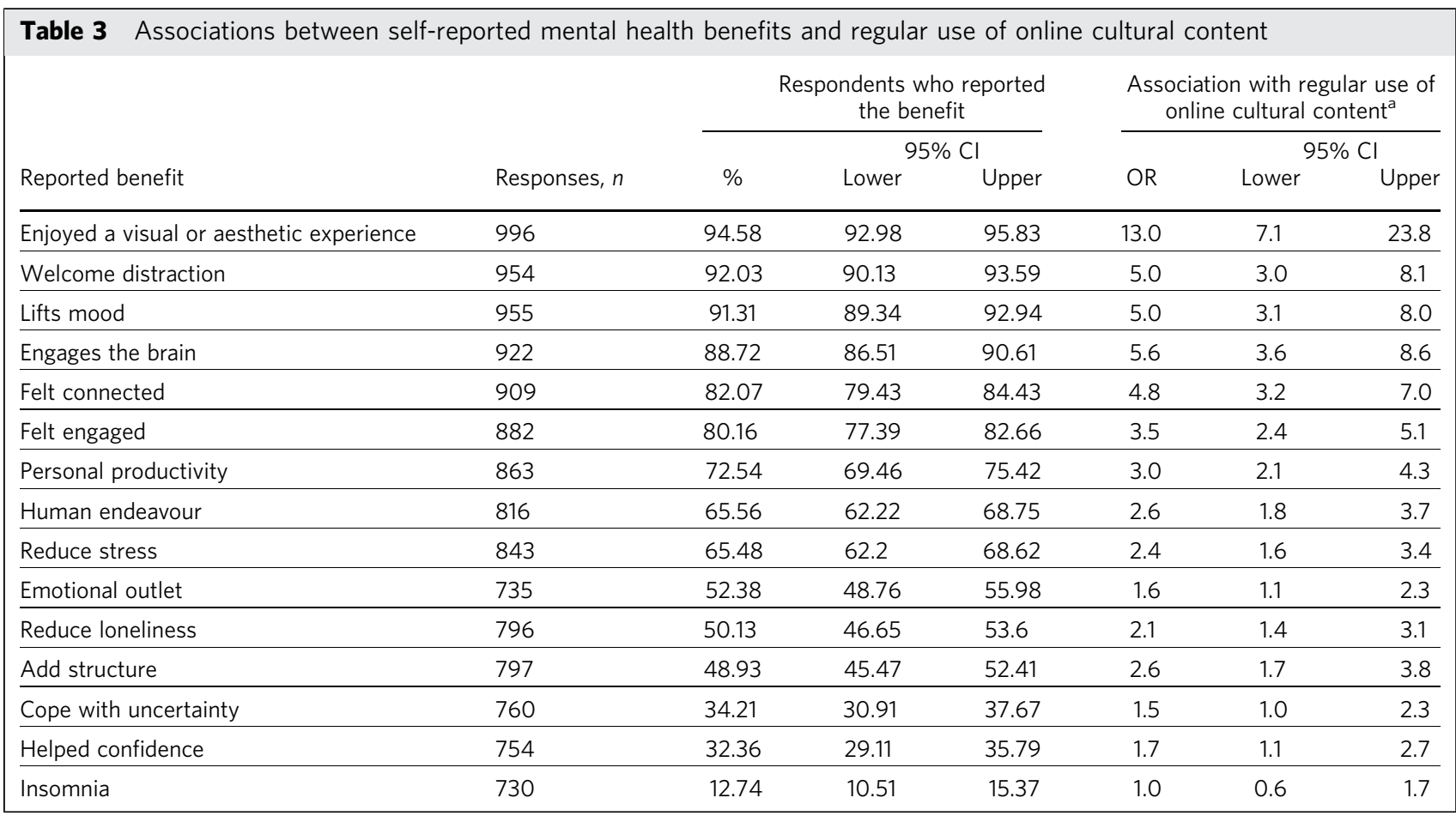

a. Regular use was defined as once a month or more.

The free-text responses from the initial survey, along with the themes developing from the analysis of the free-text survey, were integrated with the quantitative data, providing the research team a more holistic understanding of the survey results. This process ensured reflexivity and enabled the research team to confirm the trustworthiness of the emerging themes. Figure 1 reflects the findings of the free-text survey, specifically regarding responses to the question 'How is online cultural content helpful to mental health and well-being?'. Seven main themes emerged: inspiration, stimulation, learning, shifting attention, mood lifting, connection and calming. 'Shifting attention' was divided into the categories of immersion, focus, escapism, diversion and distraction, to provide a deeper analysis of the mental health effects gleaned from the shifting of participants' attention. As Fig. 1 demonstrates, many of these categories are interrelated, a finding that reflects the multifaceted way in which the participants described that online cultural content affected mental health and well-being.

\section{Discussion}

The self-reported mental health benefits of online cultural content in this study are broadly in keeping with a rich human history describing the mental health benefits of arts and culture. ${ }^{12}$ However, this survey suggests that the mental health benefits of online cultural content may currently be restricted to people within a narrow sociodemographic range. Almost all the self-reported mental health benefits are associated with regular use of online culture, and many groups at higher risk of mental health problems were least likely to have increased their use of online culture in the context of COVID-19. This suggests that inequitable engagement with cultural institutions is not being reduced by the transition to online forms of cultural engagement and that this transition may even worsen health disparities in the context of COVID-19. This is in urgent need of reversal and exploration of the potential synergies of online and in-person experiences as we emerge from COVID-19 restrictions.

The finding of overall increased use of online cultural content is broadly consistent with public perception and with another study that looked at online culture consumption more widely to include streaming music and movies as well as video games. ${ }^{20}$ The characteristics of people in our study reflect community cultural engagement in general, with high proportions being female, White, older ${ }^{40}$ and university educated. In addition, the overall profile broadly maps onto the usual onsite profile of museum users. Although this might indicate that cultural online resources are particularly helpful to this group, it seems likely that wider segments of the population might also derive benefit given equitable access to the content, as is the case with in-person engagement. ${ }^{41}$ This is particularly important given that those who are least likely to be engaging with cultural resources are those at higher risk of mental health problems during and in the aftermath of the COVID-19 pandemic, such as young people and ethnic minorities. ${ }^{4}$

We found that clinical levels of distress were associated with being young, female, lower income, lower educational attainment, previous COVID-19 diagnosis (confirmed or suspected), self-isolating, Black, Asian, Middle Eastern, mixed or other ethnic group, being in full-time education, and reporting a health problem. Although our population is not a representative population sample, these results echo 


\begin{tabular}{|c|c|c|c|c|}
\hline \multirow[b]{3}{*}{ Characteristic } & \multirow[b]{3}{*}{ Variable } & \multicolumn{3}{|c|}{$\mathrm{K} 10>19$} \\
\hline & & & \multicolumn{2}{|c|}{$95 \% \mathrm{Cl}$} \\
\hline & & OR & Lower & Upper \\
\hline \multicolumn{5}{|l|}{ Age group, years } \\
\hline & $16-24$ & 1.00 & & \\
\hline & $25-34$ & 0.52 & 0.26 & 1.06 \\
\hline & $35-44$ & 0.46 & 0.23 & 0.91 \\
\hline & $45-54$ & 0.32 & 0.17 & 0.60 \\
\hline & $55-64$ & 0.20 & 0.11 & 0.35 \\
\hline & 65 and over & 0.12 & 0.07 & 0.21 \\
\hline Gender & Female & 2.07 & 1.46 & 2.93 \\
\hline $\begin{array}{l}\text { Annual household } \\
\text { income }\end{array}$ & More than $€ 30,000$ & 0.72 & 0.55 & 0.95 \\
\hline $\begin{array}{l}\text { Highest } \\
\text { educational } \\
\text { attainment }\end{array}$ & University degree & 0.61 & 0.44 & 0.86 \\
\hline Ethnicity & $\begin{array}{l}\text { White, British, Irish } \\
\text { and other }\end{array}$ & 0.60 & 0.40 & 0.92 \\
\hline Country & UK & 1.00 & 0.74 & 1.36 \\
\hline \multicolumn{5}{|l|}{ Type of area } \\
\hline & City & 1.00 & & \\
\hline & Large Town & 0.84 & 0.59 & 1.21 \\
\hline & Small Town & 0.98 & 0.70 & 1.36 \\
\hline & Village & 0.74 & 0.53 & 1.04 \\
\hline & $\begin{array}{l}\text { Rural (hamlet or } \\
\text { isolated dwelling) }\end{array}$ & 0.59 & 0.32 & 1.08 \\
\hline \multicolumn{5}{|l|}{ Household } \\
\hline & $\underline{\text { Living alone }}$ & 1.00 & & \\
\hline & Living with one other & 1.20 & 0.88 & 1.62 \\
\hline & $\begin{array}{l}\text { Living with more } \\
\text { than one other }\end{array}$ & 1.24 & 0.84 & 1.83 \\
\hline $\begin{array}{l}\text { Previous } \\
\text { COVID-19 } \\
\text { infection }\end{array}$ & Yes or suspected & 1.70 & 1.16 & 2.48 \\
\hline \multicolumn{5}{|l|}{ Isolation status } \\
\hline & Full isolation & 1.00 & & \\
\hline & Restricted & 0.61 & 0.38 & 0.98 \\
\hline & Leaving more often & 0.58 & 0.35 & 0.95 \\
\hline
\end{tabular}

Employment

status

\begin{tabular}{lllll}
\hline & Full time education & 1.00 & & \\
\cline { 2 - 5 } & Employed & 0.37 & 0.22 & 0.63 \\
\cline { 2 - 5 } & $\begin{array}{l}\text { Unemployed/ } \\
\text { unwell/furlough/ } \\
\text { homemaker }\end{array}$ & 0.47 & 0.25 & 0.85 \\
\cline { 2 - 5 } & Retired & 0.15 & 0.09 & 0.26 \\
\hline $\begin{array}{l}\text { Physical health } \\
\text { problem/disability }\end{array}$ & Yes & 1.83 & 1.34 & 2.49 \\
$\begin{array}{l}\text { Mental health } \\
\text { problem }\end{array}$ & Yes & 4.30 & 2.99 & 6.20 \\
\hline & & & Continued
\end{tabular}

\begin{tabular}{|lllll|}
\hline Table 4 & Continued & & \\
& & \multicolumn{3}{c|}{$\mathrm{K} 10>19$} \\
\cline { 2 - 5 } & & \multicolumn{3}{c}{$95 \% \mathrm{Cl}$} \\
Characteristic & Variable & OR & Lower & Upper \\
\hline $\begin{array}{l}\text { In-person } \\
\text { museum use }\end{array}$ & Visit in previous year & $\mathbf{0 . 6 6}$ & $\mathbf{0 . 5 2}$ & $\mathbf{0 . 8 4}$ \\
\hline
\end{tabular}

K10, Kessler Psychological Distress Scale.

a. Bold denotes significant difference identified based on odds ratio.

epidemiological findings in the UK population more generally. ${ }^{3,5}$ In a lifestyle survey conducted in the UK in June 2020, rates of depression had almost doubled since before the pandemic, with high rates in young adults in particular. ${ }^{5}$ Although we used a different scale, which is designed also to detect anxiety, these associations are broadly similar.

A very high proportion of participants reported benefits to mental health from using online culture. The most commonly reported were 'Enjoyed a visual experience or aesthetic experience' and 'Provided a welcome distraction'. The range and interconnection of these perceived benefits, and further elucidation of possible mechanisms such as learning and creativity, demonstrates the complexity and multifaceted nature of the relationship between mental health and cultural experiences which has been the subject of academic interest and debate throughout the history of ideas. ${ }^{12}$ Unlike in-person cultural experiences, the benefits of online experiences are not likely to be confounded by being in an outdoors environment or walking to, from and around the cultural venue, which introduces the confounder of gentle exercise. ${ }^{9}$ Further research is necessary to explore the longevity of the perceived changes, how they map onto the core components of common mental disorders and whether their benefits can be enhanced further, especially for those with the greatest mental health need.

Reported mental health benefits were more commonly reported by regular users of online culture, suggesting that online culture confers more mental health benefits in regular users. Our understanding of the potential synergies of different modes, as well as engagement with different types of cultural content, would benefit from further study and will be of particular significance as we emerge from COVID-19 restrictions.

Young people were not only less likely to be regular users of online culture, they were also less likely to have increased their use during the COVID-19 pandemic, despite having high rates of mental disorder in this context. ${ }^{5}$ This was also the case for people from Black, Asian, Middle Eastern, mixed or other ethnicities. Minority ethnic groups have been identified as being particularly vulnerable as we emerge from the COVID-19 pandemic ${ }^{4}$ and are amongst the most reluctant help-seekers. ${ }^{42}$

In addition, there was some evidence that the reported benefits vary with age. This suggests that young people may be missing out on the potential benefits of online culture. Further research is needed to elucidate whether this is due to preference or reduced awareness of these resources and their potential mental health benefits. In addition, in these younger age groups online access to such resources may 


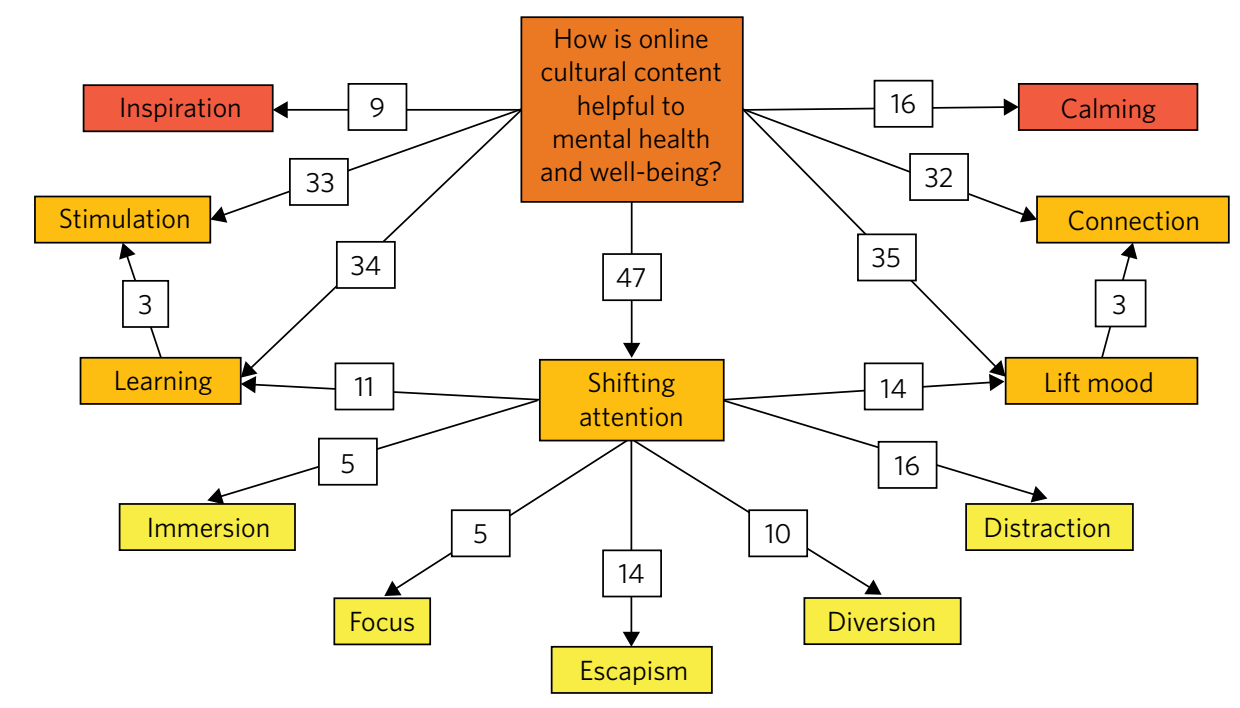

140 total codes

Fig. 1 Main themes identified in responses to the survey question: 'How is online cultural content helpful to mental health and well-being?'.

improve accessibility especially for those from rural areas and disadvantaged groups. This suggests potential utility in strategies to enhance the mental health benefits according to age. This may have the added benefit of improved engagement with particularly underserved groups.

However, the view that online resources are universally accessible is erroneous. A range of demographic, educational, economic and skills-related factors merit attention when considering who might be able to benefit from the provision of online resources. National trends in internet use indicate that a number of determinants create a 'digital divide' which might limit who is able to access online cultural content. ${ }^{43}$ For example, those over the age of 50 are less likely to have regular access to the internet. Those with educational qualifications are more likely to use the internet: nearly 19 in 20 of those who have completed higher education are regularly online, whereas only 1 in 3 without qualifications have regular access to the internet. Household income is also important: nearly all UK households above the median ( $£ 30000$ per year) have access, compared with less than 2 in 3 households with lower income (£12 500). Finally, literacy skills remain a clear obstacle to regular internet use. More than 3 in 4 regular internet users are very confident in their reading skills, whereas less than 1 in 3 of those who do not use the internet say the same. The widespread availability of online cultural content should be kept in mind so that their study and development does not continue to reinforce existing social and economic inequalities.

\section{Strengths}

This study took advantage of the world being in a state of flux, when the global COVID-19 pandemic meant that communities were driven indoors, which had an impact on levels of depression and anxiety ${ }^{3,5}$ at the population level. This cross-sectional survey was undertaken wholly during the time that UK cultural institutions had closed their doors.
In such circumstances we were able to conduct a study of the use of online culture for mental health and well-being in unprecedented times. However, as a consequence we are lacking previous similar studies with which to compare our findings.

Of the 1056 participants, almost half gave their details for follow-up research, indicating considerable engagement with the subject. A high proportion of participants reported mental health benefits from use of online cultural content. We believe that this provides initial evidence that these resources may be a credible, valued and effective approach to improving mental health and that further research is warranted both to optimise and to reliably estimate potential benefits.

\section{Limitations}

This survey used a convenience sampling strategy. This was essential in planning the study because of the time-limited nature of the initial restrictions. However, there are also clear disadvantages of this sampling strategy due to the intrinsic problem of the non-representativeness introduced by volunteer bias. In addition, as this survey was crosssectional, the direction of these associations is unclear. It may be the case that using cultural content improves mental health, or alternatively, that people who enjoy cultural content both use it more regularly and recognise more benefits than others.

\section{Conclusions}

These findings indicate that during a global pandemic that has had a catastrophic impact on mental health at the population level ${ }^{3,5}$ the move to online provision may have compounded pre-existing inequalities in access to cultural resources. Some of those with the greatest mental health needs as we emerge from the pandemic ${ }^{4}$ may be least likely 
to be benefitting from the potential mental health benefits of online culture.

Targeting cultural content to optimise mental health benefits for vulnerable groups such as young adults and ethnic minorities are a priority as we emerge from COVID-19 restrictions. In particular, it is important to identify barriers to engagement and develop interventions to increase engagement and optimise mental health benefits. These activities would benefit from taking place outside of the remit of social prescribing initiatives, as these vulnerable groups are often the least likely to seek help from healthcare services for their mental health. ${ }^{44-46}$ Access to online culture and potential synergies between online and in-person experiences provides a potential opportunities for optimisation. This study provides some initial indication that the development of cultural content for mental health would benefit from targeting by age group, enhancing the value of online cultural content as a potentially effective, acceptable and accessible non-clinical intervention for common mental health problems. Programmatic research is now required to target, develop and evaluate these resources further.

\section{About the authors}

Rebecca J. Syed Sheriff, Senior Clinical Research Fellow, Department of Psychiatry, University of Oxford; Oxford Health NHS Foundation Trust, Warneford Hospital, Oxford; and Institute of Mental Health, University of Nottingham, UK. Helen Adams, Digital Engagement Lead, Gardens, Libraries and Museums, University of Oxford, UK. Evgenia Riga, Research Assistant, Department of Psychiatry, University of Oxford, UK. Andrew K. Przybylski, Director of Research, Oxford Internet Institute, University of Oxford, UK. Laura Bonsaver, Project Officer, Ashmolean Museum, University of Oxford, UK. Laura Bergin, DPhil student, School of Anthropology and Museum Ethnography, University of Oxford, UK. Bessie O'Dell, DPhil student, Department of Psychiatry, University of Oxford, UK. Susan McCormack, Director of Public Engagement, Ashmolean Museum, University of Oxford, UK. Cathy Creswell, Professor of Developmental Clinical Psychology, Department of Psychiatry, University of Oxford, UK. Andrea Cipriani, Professor of Psychiatry, Department of Psychiatry, University of Oxford, UK. John R. Geddes, Professor of Psychiatry, Department of Psychiatry, University of Oxford, UK.

\section{Supplementary material}

Supplementary material is available online at https://doi.org/10.1192/bjb. 2021.103.

\section{Data availability}

Data is available from the authors upon reasonable request.

\section{Acknowledgements}

We to thank Margaret Glogowska for her kind advice and support with the analysis of the free-text responses.

\section{Author contributions}

R.J.S.S., S.M., E.R., H.A., A.K.P., L. Bonsaver, C.C. and J.R.G. contributed to the survery design. R.J.S.S., E.R., L. Bonsaver and H.A. contributed to the survey implementation. Statistical analysis was undertaken by R.J.S.S. and E.R.. Free text analysis was carried out by B.O., L. Bergin, L. Bonsaver. R.J.S.S., E.R., A.K.P., H.A., L. Bonsaver, L. Bergin, B.O., S.M., C.C., A.C. and J.R.G. contributed to the mauscript preperation. All authors read and approved the final manuscript.

\section{Funding}

This research was supported by University of Oxford COVID-19 Research Response Fund.

\section{Declaration of interest}

R.J.S.S. is supported by the National Institute for Health Research (NIHR) Oxford Health Biomedical Research Centre (grant BRC-1215-20005) and by the NIHR Research Professorship awarded to Professor Andrea Cipriani (grant RP-2017-08-ST2-006). A.K.P. is supported by grants from the Huo Family Foundation and the Economic and Social Research Council (ES/ T008709/1). E.R. is funded by the NIHR Efficacy and Mechanism Evaluation Programme. A.C. received research and consultancy fees from the Italian Network for Paediatric Trials (INCiPiT), CARIPLO Foundation and Angelini Pharma. The views expressed are those of the authors and not necessarily those of the UK National Health Service, the NIHR or the UK Department of Health.

\section{References}

1 Public Health England. PHE Strategy 2020-25. PHE, 2019.

2 Nochaiwong S, Ruengorn C, Thavorn K, Hutton B, Awiphan R, Phosuya C, et al. Global prevalence of mental health issues among the general population during the coronavirus disease-2019 pandemic: a systematic review and meta-analysis. Sci Rep 2021; 11(1): 10173.

3 Pierce $M$, Hope H, Ford T, Hatch S, Hotopf M, John A, et al. Mental health before and during the COVID-19 pandemic: a longitudinal probability sample survey of the UK population. Lancet Psychiatry 2020; 21 30308-4.

4 Vadivel R, Shoib S, El Halabi S, El Hayek S, Essam L, Gashi Bytyci D, et al. Mental health in the post-COVID-19 era: challenges and the way forward. Gen Psychiatry 2021; 34(1): e100424.

5 Vizard T, Davis J, White E, Beynon B. Coronavirus and Depression in Adults, Great Britain: June 2020. Office for National Statistics, 2020 (https://www.ons.gov.uk/peoplepopulationandcommunity/wellbeing/ articles/coronavirusanddepressioninadultsgreatbritain/june2020).

6 Feinstein L. 'Beginning of a new era': how culture went virtual in the face of crisis. Guardian 2020; 8 Apr.

7 Mind. The Mental Health Emergency: How Has the Coronavirus Pandemic Impacted our Mental Health? Mind, 2020.

8 Ottone E. In moments of crisis, people need culture. UNESCO 2020 29 Mar (https://en.unesco.org/news/moments-crisis-people-needculture).

9 Browne Gott H. Exploring the Relationship between Culture and Well Being. Welsh Government, 2020.

10 Manwell LA, Barbic SP, Roberts K, Durisko Z, Lee C, Ware E, et al. What is mental health? Evidence towards a new definition from a mixed methods multidisciplinary international survey. BMJ Open 2015; 5(6) e007079.

11 Public Health Agency of Canada, Mood Disorders Society of Canada, Health Canada, Statistics Canada, Canadian Institute for Health Information (eds) The Human Face of Mental Health and Mental Illness in Canada 2006. Public Health Agency of Canada, 2006.

12 Belfiore E, Bennett O. The Social Impact of the Arts: An Intellectual History. Palgrave Macmillan, 2008

13 Aristotle BJ. Complete Works of Aristotle: The Revised Oxford Translation (vol 5) (ed J Barnes). Easton Press, 2001.

14 Schopenhauer A. The World as Will and Representation. 
15 Fancourt D, Finn S. What is the Evidence on the Role of the Arts in Improving Health and Well-Being? A Scoping Review. WHO Regional Office for Europe, 2019.

16 Fancourt D, Aughterson H, Finn S, Walker E, Steptoe A. How leisure activities affect health: a narrative review and multi-level theoretical framework of mechanisms of action. Lancet Psychiatry 2021; 8: 329-39.

17 Bourdieu P. Distinction: A Social Critique of the Judgment of Taste. Harvard University Press, 1984.

18 Brook O, O'Brien D. Culture is Bad for You: Inequality in the Cultural and Creative Industries. Manchester University Press, 2020.

19 Brook O. Spatial equity and cultural participation: how access influences attendance at museums and galleries in London. Cult Trends 2016; 25: 21-34.

20 Creative Industries Policy and Evidence Centre. Digital Culture: Consumption in Lockdown. Insights from the Consumer Tracking Study. PEC, 2020.

21 Froggett L, Farrier A, Poursanidou K, Hacking S, Sagan O. Who Cares? Museums, Health and Wellbeing Research Project: A Study of the Renaissance North West Programme. University of Central Lancashire Psychosocial Research Unit, 2011

22 ArtRabbit. Lost in Time \& Space Exhibition: 24 May 2012 - 6 Jun 2012. ArtRabbit, 2012 (https://www.artrabbit.com/events/lost-in-timespace-exhibition [cited 25 Aug 2020])

23 Plumb S. Neutral territory - the gallery: a site for artists, young people and older people with dementia to collaborate. Engage 2012; 30: 21-31.

24 Coles A, Harrison F. Tapping into museums for art psychotherapy: an evaluation of a pilot group for young adults. Int J Art Ther 2018; 23: 115-24.

25 Ander E, Thomson L, Blair K, Noble G, Menon U, Lanceley A, et al. Using museum objects to improve wellbeing in mental health service users and neurological rehabilitation clients. Br J Occup Ther 2013; 76 : 208-16.

26 Van Lith T, Schofield MJ, Fenner P. Identifying the evidence-base for art-based practices and their potential benefit for mental health recovery: a critical review. Disabil Rehabil 2013; 35: 1309-23.

27 Camic PM, Chatterjee HJ. Museums and art galleries as partners for public health interventions. Perspect Public Health 2013; 133: 66-71.

28 Williams E, Dingle GA, Jetten J, Rowan C. Identification with arts-based groups improves mental wellbeing in adults with chronic mental health conditions. J Appl Soc Psychol 2019; 49: 15-26.

29 Bungay $\mathrm{H}$, Clift S. Arts on prescription: a review of practice in the U.K. Perspect Public Health 2010; 130: 277-81.

30 Thomson LJ, Morse N, Elsden E, Chatterjee HJ. Art, nature and mental health: assessing the biopsychosocial effects of a 'creative green prescription' museum programme involving horticulture, artmaking and collections. Perspect Public Health 2020; 140: 277-85.

31 Stickley T, Hui A. Social prescribing through arts on prescription in a U.K city: participants' perspectives (part 1). Public Health 2012; 126: 574-9.
32 Stickley T, Hui A. Social prescribing through arts on prescription in a U.K. city: referrers' perspectives (part 2). Public Health 2012; 126: 580-6.

33 Vijayaraghavan M, Tochterman A, Hsu E, Johnson K, Marcus S, Caton CL. Health, access to health care, and health care use among homeless women with a history of intimate partner violence. J Community Health 2012; 37: 1032-9.

34 Estevao C, Fancourt D, Dazzan P, Chaudhuri KR, Sevdalis N, Woods A, et al. Scaling-up Health-Arts Programmes: the largest study in the world bringing arts-based mental health interventions into a national health service. BJPsych Bull 2021; 45: 32-9.

35 Kessler RC, Andrews G, Colpe LJ, Hiripi E, Mroczek DK, Normand SL, et al. Short screening scales to monitor population prevalences and trends in non-specific psychological distress. Psychol Med 2002; 32 959-76.

36 Andrews G, Slade T. Interpreting scores on the Kessler Psychological Distress Scale (K10). Aust N Z J Public Health 2001; 25: 494-7.

37 Perini SJ, Slade T, Andrews G. Generic effectiveness measures: sensitivity to symptom change in anxiety disorders. J Affect Disord 2006; 90: $123-30$.

38 Kessler RC, Andrews G, Colpe LJ, Hiripi E, Mroczek DK, Normand SL, et al. Short screening scales to monitor population prevalences and trends in non-specific psychological distress. Psychol Med 2002; 32: 959-76.

39 Braun V, Clarke V. Using thematic analysis in psychology. Qual Res Psychol 2006; 3: 77-101.

40 The Audience Agency. Museums Audience Report. The Audience Agency, 2018

41 Mak HW, Coulter R, Fancourt D. Associations between community cultural engagement and life satisfaction, mental distress and mental health functioning using data from the UK Household Longitudinal Study (UKHLS): are associations moderated by area deprivation? BM Open 2021; 11(9): e045512.

42 Rickwood DJ, Deane FP, Wilson CJ. When and how do young people seek professional help for mental health problems? Med J Aust 2007; 187(suppl 7): S35-9.

43 Blank G, Dutton W, Lefkowitz, J. OxIS 2019: Digital divides in Britain are narrowing but deepening. SSRN, 2020; 19 Jan. Available from: http:// dx.doi.org/10.2139/ssrn.3522083.

44 Kwan B, Rickwood DJ. A systematic review of mental health outcome measures for young people aged 12 to 25 years. BMC Psychiatry 2015; 15: 279.

45 Biddle L, Gunnell D, Sharp D, Donovan JL. Factors influencing help seeking in mentally distressed young adults: a cross-sectional survey. Br J Gen Pract 2004; 54: 248-53.

46 Memon A, Taylor K, Mohebati LM, Sundin J, Cooper M, Scanlon T, et al. Perceived barriers to accessing mental health services among black and minority ethnic (BME) communities: a qualitative study in Southeast England. BMJ Open 2016; 6(11): e012337.

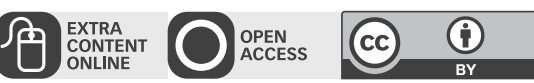

